Boise State University

ScholarWorks

9-1-2011

\title{
The Diagnosis of Mental Disorders in Clinical Social Work: A Review of Standards of Care
}

Daniel Harkness

Boise State University 


\title{
The Diagnosis of Mental Disorders in Clinical Social Work: A Review of Standards of Care
}

\author{
Daniel Harkness \\ Boise State University
}

\begin{abstract}
Licensed to diagnose and treat mental disorders, clinical social workers have begun to develop and practice professional standards of care commensurate with their status as the nation's largest provider of mental health care. Against the backdrop of malpractice claims and awards, this paper reviews the extant standards promulgated by our professional organizations, regulatory bodies, health-insurance and managed-care entities, and the courts to synthesize standards of care for the diagnosis of mental disorders. The limited available evidence suggests that clinical social workers merit congratulations and concern as we rise to the challenge of addressing those standards in education and practice.
\end{abstract}

Clinical social work has eclipsed psychiatry in the marketplace of health care. As the role and scope of psychiatry in health care have narrowed and contracted (Bennet, 2000; Gabbard \& Kay, 2001; Olfson, Marcus, \& Pincus, 1999; Ramin \& Olfson, 2008; Wilk, West, Narrow, Rae, \& Regier, 2005), the role and scope of clinical social work have expanded. With an estimated 170,790 clinical social workers certified or licensed to assess, diagnose, and treat mental disorders in the United States (Center for Workforce Studies, 2006; Dwight Hymans, personal communication, June 24, 2008), and perhaps another 94,500 licensed social workers receiving clinical supervision (Center for Workforce Studies, 2006), clinical social work has become the nation=s largest provider of mental health services (Center for Workforce Studies, 2006), surpassing the 38,000 psychiatrists practicing in the United States (APA, 2009) by a factor greater than four.

A license to practice clinical social work typically requires a master=s degree in social work (MSW), two or more years of full-time, supervised, postgraduate clinical experience, and passing a written examination (NASW, 2005a; ASWB, 2008). Among the putative rewards of clinical licensure are greater authority, autonomy, income, prestige, privilege, and work satisfaction (Center for Workforce Studies, 2006), but counterbalancing those rewards is the liability of the specialist (ASWB, 1998) to provide a higher standard of care (Reamer, 2003). This article reviews standards of care for the diagnosis of mental disorders in clinical social work.

\section{Diagnosis in Clinical Social Work}

Diagnosis is the procedure used to identify the presence, nature, and cause of a disorder from its onset, course, and constellation of signs and symptoms (Othmer \& Othmer, 2002). Used to differentiate among more than 400 mental disorders (APA, 2000), the purpose of diagnosis is to provide guidance for treatment (Frazer, Westhuis, Daley, \& Phillips, 2009; U.S. Department of Health and Human Services, 1999). Granting that a "correct" diagnosis is not a guarantee of "correct" treatment, given the state of the art (Zimmerman, 2003), diagnosis is important nevertheless because the iatrogenic consequences of misdiagnosis can be catastrophic (Betts, 2002; Charles, 2001; Jordan \& Stein, 2000; Morrison, 1997; Priest, 1997; Wallen \& Lorman, 2008).

Clinical social workers are often the first to diagnose mental disorders (NASW, 2005a), and the courts have upheld our authority to do so as licensed clinicians (In re ADOPTION/ GUARDIANSHIP NO. CCJ14746, 2000; People v. R.R. and People v. G.A., 2005; Siegel, 2008). By the same token, practicing with a license to diagnose mental disorders makes clinical social workers liable for their diagnoses (Reamer, 2003). Liability is a legal term that means an obligation or duty of care owed a client (Black, 1968), and any failure to diagnose or misdiagnosis of a mental disorder (Kirk \& Kutchins, 1988) that results in harm to the client may become a cause of malpractice (Kutchins \& Kirk, 1987). 
Reamer (1995) has described failures to diagnose, misdiagnoses, and (their logical sequelae) incorrect treatments as among the most frequent malpractice claims filed against social workers. And although social work malpractice is rarely proven (Corcoran, 1998), in Danzon and Lillard's (1983) landmark study of the disposition of 5,832 medical malpractice claims, $43 \%$ were dropped without payment, $51 \%$ were settled with payment out of court, and $7 \%$ were litigated to a verdict, with the plaintiff winning roughly one in four or $1.9 \%$ of the time. Thus findings of malpractice may represent the tip of an iceberg if, as Boland-Prom (2009) has reported, 10\% of the NASW membership insured by NASW Assurance Services have had malpractice claims against them.

Although insurers are generally reluctant to provide information about malpractice claims, NASW Assurance Services generously provided summary statistics for this article, indicating that failures to diagnose and incorrect diagnoses have accounted for a mere $1.39 \%$ of its claims since the inception of the program, approximately 40 years ago, through December 31, 2008, with incorrect treatment's accounting for 23.65\%, and the combination comprising 25.04\% (L. B. Klapthor, NASW Assurance Services, personal communication, November 5, 2009).

Not all malpractice claims are settled or go to court, as we have seen, but all malpractice claims against clinical social workers (and all other licensed health care providers) that end in payments must be reported to the National Practitioner Data Bank (NPDB) under Title IV of Public Law 99-660 (U.S. Department of Health and Human Services, 2006). Although information provided to the NPDB is confidential (and can only be provided to authorized inquirers, such as hospitals, managed care organizations, and State licensing agencies for professional credentialing, licensing, and peer-review purposes), the NPDB maintains a deidentified Public Use Data File to facilitate research. Based on statistical analysis of the "disclosable" reports found in the Public Use Data File, malpractice insurance companies, state insurance guarantee funds, and other mandated reporters made malpractice payments for 233 clinical social workers from September 1, 1990 through June 30, 2009 (NPDBPUDF, June 30, 2009). The majority of those payments represented malpractice settlements, but for judgments and settlements combined the mean payment was $\$ 367,866.67$, with a minimum payment of $\$ 3,500$, a median payment of $\$ 47,500$, and a maximum payment of $\$ 1,950,000$. Although the nature of the malpractice allegations that led to settlements or judgments were withheld or missing for 54 of the 233 clinical social workers in the NPDBPUDF, 11 of the 179 valid allegations (6.15\%) were diagnosis-related (e.g., failure to diagnose or wrong or misdiagnosis), and 64 (35.75\%) were treatment-related (e.g., failure to treat, improper management, improper technique, or wrong procedure or treatment). In summary, diagnostic and treatment errors represented $41.9 \%$ (75) of awards for social work malpractice.

Diagnostic errors rarely become causes of action for malpractice, and diagnostic errors represent a small percentage of malpractice claims and awards. Incorrect treatments rarely become causes of action as well, but they represent the largest percentage among causes for malpractice claims and awards, and incorrect treatments, by definition, are the sequelae of diagnostic errors or failures to utilize correct diagnoses as guidance for treatment. Moreover, as failures to diagnose, incorrect diagnoses, and incorrect treatments represented $25 \%$ of malpractice claims but $42 \%$ of malpractice awards, it appears that claims related to diagnosis and treatment are more likely than other claims to end in malpractice judgments and settlements. Thus, as foreshadowed more than 20 years ago by Kutchins and Kirk (1987), the differential diagnosis of mental disorders has become a sine qua non in clinical social work.

\section{Standards of Care for the Diagnosis of Mental Disorders}

Traditionally, “[s]ocial workers have [had] an obligation to deliver services consistent with the profession's standard of care . . . in the way that an ordinary, reasonable, and prudent social worker would act under the same or similar circumstances ..." (Reamer, 1998, p. 597), but the practice of clinical social work has become highly-regulated in the shifting matrix of private interests and public concerns (Corcoran, 1998; Howard \& Jenson, 1999; Munson, 2004; Rosen \& Proctor, 2003; Rubin \& Parrish, 2007). Independent professional organizations, like the National Association of Social Workers (NASW, 2005a, 2005b) and the American Board of Examiners in Clinical Social Work (ABE, 2002), publish multiple practice guidelines for clinical social work, and the 50 individual state boards of social work examiners that license social workers for clinical practice administer 50 different legislative standards designed to protect the public (ASWB, 2008). Private and public third-party entities (e.g., Blue Cross, Blue Shield, CHAMPUS, 
Magellan Behavioral Health, Medicaid, etc.) that pay for clinical social work services have adapted or adopted a variety of practice standards developed by the American Psychiatric Association, the U.S. Substance Abuse and Mental Health Services Administration, and others to manage health care and costs (Munson, 1997). Finally, the courts have applied, interpreted, and occasionally decreed standards, such as the "Duty to Warn" (e.g., Tarasoff v. Regents of the University of California), used to distinguish between practice and malpractice in the 50 United States (Peters, 2000).

\section{Professional Standards}

In the NASW Standards for Clinical Social Work (NASW, 2005a) the nation=s largest organization of professional social workers (NASW, 2005a, p. 9) observes that clinical social work includes the diagnosis of mental and behavioral disorders. The only language that addresses diagnosis in those standards, however, is an affirmation that clinical social workers "shall be prepared for the challenges that encompass the assessment ... of people with mental disorders and behavioral or emotional disturbances.@

NASW Standards for Social Work Practice in Health Care Settings (NASW, 2005b) provide somewhat more guidance. Social workers are to assess their clients on an ongoing and comprehensive basis and develop treatment strategies and interventions on the basis of information that includes: (1) the client's past and current health status; (2) the impact of any health conditions or treatments on client functioning; (3) a social history of the client that includes developmental issues, work and school, and current living arrangements and household environment; (4) the client's mental status and current level of functioning, including psychiatric history, suicide risk, and coping styles; and (5) diagnoses.

Asserting that the diagnosis of mental disorders is among the main purposes of clinical social work, the ABE is a second organization that publishes practice standards for clinical social work. In Professional Development and Practice Competencies in Clinical Social Work, the first of two standard-setting documents, ABE (2002) describes the acquisition of diagnostic knowledge and skill as a stepwise developmental process that may take five or more years to complete. At the advanced or expert level, the clinical social worker is expected to apply understanding of cultural, experiential, cognitive, and historical determinants of behavior to differential diagnosis, incorporate multiple causal models and demonstrate accuracy in complex differential diagnoses, and assure that assessments and diagnoses are free from the influence of personal and cultural issues. The second ABE document proposes a regulatory standard linked with social work licensure.

\section{Regulatory Standards}

In 1998, the Association of Social Work Boards (ASWB) that regulate social work practice published a model social work practice act reflecting contributions from accrediting bodies, credentialing groups, professional organizations, and state and national social work regulatory associations and boards. Addressing diagnosis 14 times, the ASWB Model Social Work Practice Act provides definitions and practice standards (to and from which the 50 states adhere or deviate in various degrees) in the service of public protection. Key provisions of the Act provide that clinical social workers are: (1) qualified to use the Diagnostic and Statistical Manual of Mental Disorders (DSM) (APA, 2000), the International Classification of Diseases (World Health Organization, 2007), and other diagnostic classification systems in the assessment and diagnosis of mental, emotional, and behavioral disorders, conditions, and addictions; (2) prohibited from discriminating against clients on the basis of diagnosis; and (3) mandated to (a) base services on an assessment or diagnosis, (b) evaluate on an ongoing basis whether an assessment or diagnosis needs to be reviewed or revised, (c) follow standard and accepted procedures for deciding when and how to use an assessment or diagnostic instrument, (d) inform clients of their purpose before administering diagnostic instruments and, when available, of their results, (e) develop service plans and goals based on the assessment or diagnosis, and (f) document the assessment or diagnosis in the client chart or record of service.

Building on the work of the model practice act published by ASWB, in 2008 ABE published a Model Practice Act for Clinical Social Work that defines diagnosis and asserts additional practice standards. Diagnosis is Athe non-medical [sic] process of using a biopsychosocial framework to discern impairments and disabilities in terms of the 
characteristics of mental, emotional, behavioral, developmental, and addictive disorders, consistent with accepted classification systems” (p. 7). For clinical social workers, the diagnostic process is governed by five practice standards: (1) services shall be based upon an assessment or diagnosis; (2) the assessment or diagnosis shall be evaluated on an ongoing basis to determine whether review or revision is required; (3) proper training and informed consent shall be required before any assessment or diagnostic instrument is used with a client, and the client shall be informed of the results, when available; (4) the plan for services shall be developed with the client and include goals based on the assessment or diagnosis; and (5) the assessment or diagnosis and any revisions shall be documented in the clinical record.

\section{Third-party Standards}

Much as Parloff (1982) predicted in Bambi meets Godzilla, third-party standards of care for mental disorders now hinge on their diagnosis and treatment in accordance with Amedical necessity," a slippery construct that spans five dimensions, according to Rosenbaum, Kamoie, Mauery, \& Walitt (2003). The first and fundamental dimension of medical necessity is a function of contractual scope, the third party's determination that its policy provides coverage for a recommended procedure or treatment, and that the recommended treatment is required to restore the patient to normal functioning. The second dimension is standard of practice, a determination that the recommended procedure or treatment is consistent with the professional standard of care. The third dimension is patient safety and setting, a determination that the procedure or treatment will be delivered in the safest, least-intrusive manner. The fourth dimension, medical service, is a determination that the procedure or treatment is of a medical nature, and not a "social or nonmedical treatment” (p. 3). The fifth and final dimension of medical necessity is its cost, a determination "by the insurer" (p.3), once again, that the recommended treatment is cost-effective.

The precise algorithms that third parties use to determine medical necessity in the diagnosis and treatment of mental disorders have not been reported in detail, because those are proprietary, closely-held secrets (Rosenbaum, et al. 2003). Yet confidential interviews with key informants from the industry, as well as a review of judicial case law, official investigations, and legal actions, support the conventional wisdom that insurers and insuring organization restrict coverage to essential treatments of mental disorders defined by the DSM, diagnosed in accordance with generally-accepted practice, and documented with a detailed description of the constellation of congruent signs and symptoms supporting each diagnosis (Rosenbaum et al., 2003).

\section{Common-law Standards}

The common law is established in court, and the courts have begun to take notice that clinical social work has become the nation=s primary profession licensed for the assessment, diagnosis, and treatment of mental disorders. Wrestling with the question of a clinical social worker's duty to protect client confidentiality by refusing to release psychotherapy records to a lower court, for example, the United States Supreme Court elevated our status by affirming an evidentiary privilege for clinical social work in Jaffe $v$. Redmond, under which "confidential communications between a [licensed clinical social worker] and her patients in the course of diagnosis or treatment are protected from compelled disclosure under Rule 501 of the Federal Rules of Evidence.”

Clinical social workers were delighted, of course, when the Jaffe decision conferred upon clinical social work the professional privilege accorded psychiatry and psychology. But "[T]o make a profession in the genuine sense, something more than a mere [license or privilege] is needed. There are certain objective standards ..." (Flexner, 1915), hence the courts have created common law, incrementally, with standards in mind, to counterbalance the privileges of helping professions with proportional obligations and duties (Kutchins, 1991).

Broadly, in common law, licensed clinical social workers owe a duty to their clients to provide an appropriate standard of care (Reamer, 2003). Any deviation from that standard of care which harms or injures the client may constitute the tort of malpractice, a determination made in "the legal system [which] normally acts as a control over activities that cause injuries, holding those involved accountable for progress within a field and judging the standards by which the 
activity is performed" (Furrow, 1980, 23-24). Although a few courts have ruled that social workers cannot commit malpractice, because social work is not a profession and lacks a standard of care (Corcoran, 1998; Saltzman \& Proch, 1990), most courts now treat clinical social workers in the same manner as physicians and other healthcare providers, using expert witnesses to establish the relevant standard (Reamer, 2003; Siegel, 2008). Expert witnesses are used because tort law has traditionally given the helping professions the privilege of setting their own legal standards of conduct (Keeton, Dobbs, Keeton, \& Owen, 1984). Like physicians, clinical social workers have traditionally been shielded from liability if their behavior has been consistent with customary practice (Reamer, 2003). Where "customary practice" is hard to pin down because clinical social workers follow more than one school of thought, those who practice in accordance with a "respectable minority" of their peers have also been shielded from liability under common law (Reamer, 2003).

In some states, customary practice is still based upon the "locality rule," which requires testimony from expert witnesses who practice in the same community (e.g., that area served by the local hospital) to establish the local standard of care (Lillard, 2008).

However, judicial deference to physician customs is eroding. Gradually, quietly and relentlessly, state courts are withdrawing this legal privilege. Already, a dozen states have expressly rejected deference to medical customs and another nine, although not directly addressing the role of custom, have rephrased their standard of care in terms of the reasonable physician, rather than compliance with medical custom. (Peters, 2000, p. 163).

As a result, many states have adopted a more stringent "national rule," reflecting the practice of "reasonable and prudent" clinicians across the nation, meaning those who stay abreast of the latest professional developments (Meyer \& Simon, 2004; Williams, 2004).

Even more important than the raw numbers is the trend revealed by the [Court] decisions. The slow but steady judicial abandonment of deference to medical custom began in earnest in the 1970s, continued in the 1980s, and retained its vitality through the 1990s. Showing no signs of exhaustion, this movement could eventually become the majority position. (Peters, 2000, p.163).

Accordingly, common-law standards of care continue to change. Arguing, for example, that A[t]he role of science in medicine has increased dramatically in recent decades," and that A[t]he increased prominence of science has improved health care by showing that many widely-accepted medical practices are not only ineffective but, in some cases, injurious," Williams (2004, p. 479) has predicted that the courts will bring practice customs into compliance with evidence-based models of care by establishing standards of care from the bench.

Asked to comment on William=s prediction, an experienced trial judge dissents from retirement.

I did medical malpractice for many years. My experience is that courts don't set the standard of care. An expert witness (sometimes dueling expert witnesses) defines the standard and the jury picks which standard they like and decides whether the facts prove that the standard was violated. I suspect the same is true for social work malpractice. (The Honorable D. Hensley, personal communication, June 27, 2008).

But in another context and venue, Williams (2004) proved prescient. In 2005 a New York Supreme Court addressed challenges to the diagnostic authority and expertise of clinical social work in two cases, People v. R.R. and People v. G.A., holding that "the diagnosis and treatment of mental disorders that are organic or result from physical ailment" were within the scope of practice for clinical social work. As though to balance the privileges of clinical social work with congruent duties, the Court "rendered a long and detailed decision ... concerning the scope of practice for clinical social workers in diagnosis and treatment of mental disorders” (Siegel, 2008, p. 157), advancing a more robust standard of care in its 18,439-word opinion. 
Asserting that differential diagnosis is the key to appropriate and effective healthcare planning and treatment, the New York Court defined diagnosis as "the process of distinguishing, beyond general social work assessment, between similar mental . . . disorders . . . within a psychosocial framework on the basis of their similar and unique characteristics consistent with accepted classification systems," and rendered our standard of care as a set of assessment procedures that clinical social workers must follow "as a matter of law.” Those procedures, to paraphrase the Court, are those of a comprehensive and holistic biopsychosocial client assessment: (1) taking a systematic history of the onset, course, and treatment of presenting disorders, (2) conducting a mental status examination, (3) gathering information and observing signs related to the physical condition and symptoms, health history, medications utilized, substance use and abuse, and allergies of the client as part of an initial assessment, (4) screening "for mental or physical symptoms which may have physical causes or portend the existence of physical illness" throughout the course of evaluation and treatment, and (5) assessing [and treating] those disorders, as necessary, through referral to or consultation with other health care professionals, including psychological and other diagnostic testing. Designed to generate the empirical data base required for differential diagnosis and treatment, the Court concluded, these are the elements of our standard of care.

\section{Performance Appraisal}

This article has reviewed professional, regulatory, third-party, and common-law standards of care for the diagnosis of mental disorders in clinical social work. The common thread in the standards of care reviewed here is that clinical social workers must follow a standard set of assessment procedures, including the mental status examination (Siegel, 2008), in order to generate the empirical data required to distinguish, among many disorders, those that may contribute to our clients= objective and subjective distress, impinge on their achievement of personal goals, and suggest or require different treatments.

Although social workers have been described as ambivalent (Newman, Clemmons, \& Dannenfeiser, 2007), cavalier (Kutchins \& Kirk, 1988), deceptive (Kirk \& Kutchins, 1988; Rubinson, 1999), pragmatic (Corcoran \& Walsh, 2006; Dzieglielewski, Johnson, \& Webb, 2002; Kutchins \& Kirk, 1988), squeamish (Jordan \& Franklin, 2003; Kutchins \& Kirk, 1988; McQuaide, 1999), and wary (Turner, 2002) about diagnosis, how clinical social workers diagnose mental disorders, and the extent to which they practice diagnosis in accordance with the standards reviewed here, is largely unknown. By-and-large, the evidence that we do have is drawn from two sources. The first source is malpractice claims and payments, from which perhaps little can be inferred with confidence about social work practice at large. The second source is findings from surveys that have asked respondents to "diagnose" paper-and-pencil analogue cases (e.g., Kirk \& Hsieh, 2009; Kirk, Wakefield, Hsieh, \& Pottick, 1999; Muniz, 1999; Rubinson, 1999). Designed for ease of analysis, case-analogue research is used to test clinicians' knowledge and memory of DSM criteria for the diagnosis of an episode of major depression, for example. In order to participate in analogue research, however, survey respondents must formulate diagnostic impressions without observing the client, without obtaining a history of the onset and course of presenting concerns, without conducting a mental status examination, and without the nuance and texture of a face-to-face interview. This invokes a dubious standard of care that may shed little light on how clinical social workers diagnose mental disorders with flesh-and-blood clients, especially as clinicians are "struggling to conduct diagnostic evaluations more efficiently in the face of decreasing reimbursement rates@ (Zimmerman, 2003, p. 282).

With these limitations in mind, our performance appears to deserve congratulations and, withal, warrant concern. Notwithstanding the flawed "reliability" of the DSMs (Kutchins \& Kirk, 1986) and social workers' ambivalence about applying diagnostic labels to clients (Kirk \& Kutchins, 1988), congratulations are in order because there have been few settlements or judgments against clinical social workers for diagnostic malpractice, for breaching an evolving standard of care. Yet all standards of care rest on the assumption that the health care outcomes over which we have control can be no better than the procedures we follow, and our procedures have been called into question by evidence from survey research suggesting that clinical social workers may misdiagnose mental disorders somewhat frequently, both deliberately (Ginsberg, 2009; Kirk \& Kutchins, 1988; Muniz, 1999; Rubinson, 1999) and unintentionally (Flanagan \& Ahn, 2006; Muniz, 1999; Rubinson, 1999). 
The perceived frequency with which social workers commit diagnostic errors led Kutchins and Kirk (1987) to question whether clinical social workers should diagnose mental disorders at all, fearing that schools of social work could not have prepared them to evaluate the organic aspects of mental disorders, the first in a series of determinations that must be made to differentiate among mental disorders in accordance with the hierarchical organization of the DSM. Concerns about the training of clinical social workers also formed the basis for the dissenting opinion in Jaffee $v$. Redmond, in which Justice Scalia argued, "It is not clear that the degree in social work requires any training [in the assessment, diagnosis, and treatment of mental disorders] . . comparable in its rigor . . . to the training of the other experts ..." Similar concerns were raised by the standard-setting court in People v. R.R. and People v. G.A. (2005), which noted,

[T] hese licenses ... place a heavy burden ... on . . clinical social workers ... [and] the professional schools which train them [because] the failure ... of a licensed clinical social worker to utilize a biopsychosocial approach in the performance of diagnosis, assessment and treatment planning would constitute practice that, per se, violates the professional standard of care.

To put things in perspective, however, it appears that psychiatrists share our ambivalence about diagnosis (Rubinson, 1999; Taylor \& Vaidya, 2005). Moreover, psychiatrists misdiagnose mental disorders as well (Flanagan \& Ahn, 2006), both deliberately and unintentionally (Muniz, 1999; Rubinson, 1999), although they may be somewhat better diagnosticians than clinical social workers (Flanagan \& Ahn, 2006; Shimabukuro, 2008; Rubinson, 1999). If that edge reflects differences between social work education and medical training, then perhaps more congratulations are in order, because schools of social work are providing more classroom training in the use of the DSM than they have in the past (Newman, Clemmons, \& Dannenfeiser, 2007).

Newman, Clemmons, and Dannenfeiser (2007) surveyed the 175 graduate schools of social work accredited by the Council on Social Work Education to determine the extent to which each program included content on the DSM in their curriculum. From at least 35 states, 104 questionnaires were returned, and 77 schools reported offering a specific course on the DSM, "with the amount of content ranging from 5\% to 100\% [and] averaging 75\%" (Newman et al., 2007, p. 301). Contrast this with the findings of Taylor and Vaidya (2005), who conducted a similar survey of the 149 accredited psychiatry training programs in the United States. Of the 68 programs that responded, about " $50 \%$ [did] not teach any course in the use of DSM at all" (Taylor \& Vaidya, 2005. P. 248), although more than 3/4 offered a course in mental status examination. In contrast, $74 \%$ of the 104 schools of social work that responded to the survey by Newman, et al. (2007) offered a specific course on the DSM. Notably, in 50 schools the course was required, and an average of $75 \%$ of the students took the course, whether required to or not.

The report that schools of social work are paying increased attention to DSM content in the classroom is encouraging, because the DSM is the standard compendium of the mental disorders that clinical social workers are licensed to diagnose. However, the same report also raises questions about how social workers are being trained, beyond pattern recognition, in the clinical assessment, reasoning, and judgment upon which diagnosis depends (APA, 2000; Bisman, 1999; Corcoran \& Walsh, 2006; Gambrill, 1990; Jordan \& Franklin, 2003). On one hand, Newman et al. (2007) contend that DSM content should be taught as human behavior, because "when [it] was offered in the human behavior sequence, more of the course tended to be devoted to the disorders of the DSM than in practice courses," adding "the $D S M$ is a way of naming and categorizing behavior and should not be the focus of practice" (p. 304). On the other hand, DSM content is a focus of social work practice in key texts, by Corcoran and Walsh (2006) and Jordan and Franklin (2003), for example, that introduce diagnosis, hand-in-glove, with clinical assessment, clinical reasoning, and treatment planning.

In the abstract, both educational positions have merit. The paperback edition of the current DSM weighs approximately four pounds and numbers 942 pages, following the front matter, table of contents, and introduction. This is a very large meal indeed, and Newman et al. (2007) are wise to insist that our students need time to digest it. Yet, as schools of social work embrace competency-based education (Holloway, Black, Hoffman, \& Pierce, 2009), perhaps the standards of care used by judges and juries to distinguish between social work practice and malpractice should be added to the yardsticks we use to take the measure of lessons taught and learned in the classroom. Thus, 
This is an author-produced, peer-reviewed version of this article. The final publication is available at www.springerlink.com. Copyright restrictions may apply. DOI: 10.1007/s10615-010-0263-8

although teaching diagnosis as social work practice may mean devoting less of a course to the range of disorders found in the DSM, learning diagnosis in any other context should be a reason for concern, because "[t]he diagnostic categories, criteria, and textual descriptions [of the $D S M$ ] are meant to be employed by individuals with appropriate clinical training and experience," using "guidelines to be informed by clinical judgement” (APA, 2000, p. xxxii). Finally, to the extent that instructors strive to link the differential diagnosis of a mental disorder with algorithms and contraindications for its treatment, teaching DSM content and the diagnosis of mental disorders as social work practice speaks to the malpractice distinction between "correct" and "incorrect" treatments.

Against the backdrop of malpractice claims and awards, this paper has reviewed the professional, regulatory, third-party, and common-law standards of care that govern our practice as diagnosticians. How well are we meeting those standards? Although a modest body of evidence suggests that our performance both deserves congratulations and warrants concern, licensed clinical social workers have a professional duty to assess their own preparation for meeting the diagnostic standards of care reviewed here, and to calibrate their practice accordingly. 


\section{References}

American Board of Examiners in Clinical Social Work. (2002). Professional development and practice competencies in clinical social work. Retrieved on May 20, 2008 from http://www.abecsw.org/images/Competen.PDF

American Board of Examiners in Clinical Social Work. (2008). A model practice act for clinical social work. Retrieved June 3, 2008 from http://www.abecsw.org/images/Center\%20Model\%20Practice\%20Act\%20Final\%205.22.08.pdf

Association of Social Work Boards. (1998). Model Social Work Practice Act. Retrieved May 19, 2008 from www.aswb.org/Model_law.pdf).

Association of Social Work Boards. (2008). Social Work Laws \& Regulations Comparison Database. Retrieved on June 3, 2008 from http://www.datapathdesign.com/ASWB/Laws/Prod/cgi-bin/LawWebRpts2DLL.dll/EXEC/0/02extj71udkuiz1 3q4r210lqfco2.

American Psychiatric Association. (2000). Diagnostic and Statistical Manual of Mental Disorders IV-TR. Washington, DC: Author.

American Psychiatric Association. (2009). (Retrieved on September 19, 2009 from http://www.psych.org/).

Bennet, M. (2000). Retraining the practicing psychiatrist. Psychiatric Services, 51(7): 932-934.

Betts, T. (2002). Epilepsy--doctor's dilemma, lawyer's delight? Seizure: The Journal Of The British Epilepsy Association, 11(Suppl A), 75-84.

Bisman, C. (1999). Social work assessment: Case theory construction. Families in Society, 80(3), 240-246.

Black, H. (1968). Black's law dictionary (4 ${ }^{\text {th }}$ ed., Rev.). St. Paul, Minnesota: West Publishing Co.

Boland-Prom, K. (2009). Results from a national study of social workers sanctioned by state licensing boards. Social Work, 54(4), 351-360.

Center for Workforce Studies. (2006). Licensed Social Workers in the U.S., 2004 (Volume II, Supplement). Washington, DC: National Association of Social Workers.

Charles, L. (2001). Strategies to reduce misdiagnosis of bipolar depression. Psychiatric Services, 52(1), 51-55.

Corcoran, J., \& Walsh, J. (2006). Clinical assessment and diagnosis in social work practice. New York: Oxford University Press.

Corcoran, K. (1998). Clients without a cause: Is there a legal right to effective treatment? Research on Social Work Practice, 8(5), 589-596.

Danzon, P., \& Lillard, L. (1983). Settlement out of court: The disposition of medical malpractice claims. Journal of Legal Studies, 12(2), 345-377.

Dziegielewski, S., Johnson, A., \& Webb, E. (2002). DSM-IV and social work professionals: A continuing education evaluation. Social Work in Mental Health, 1(1), 27-41. 
Flanagan, E., \& Ahn, W. K. (2006). Clinicans' familiarity with and beliefs about the causal bases of mental disorders. (Unpublished paper, Yale University School of Medicine).

Flexner, A. (1915). Is social work a profession? In National Conference of Charities and Corrections, Proceedings of the National Conference of Charities and Corrections at the Forty-second annual session held in Baltimore, Maryland, May 12-19, 1915. Chicago: Hildmann.

Frazer, P., Westhuis, D., Daley, J., \& Phillips, I. (2009). How clinical social workers are using the DSM-IV: A National Study. Social Work in Mental Health, 7(4), 325-229.

Furrow, B.R. (1980). Malpractice in psychotherapy. Lexington, Mass.: Lexington Books.

Gabbard, G., \& Kay, J. (2001). The fate of integrated treatment: Whatever happened to the biopsychosocial psychiatrist? American Journal of Psychiatry, 158(12): 1956-1963.

Gambrill, E. (1990). Critical thinking in clinical practice. San Francisco: Jossey-Bass.

Ginsberg, M. (2009). Description of private practitioners reaction to managed care. Doctoral dissertation, Adelphi University.

Holloway, S., Black, P., Hoffman, K., \& Pierce, D. (2009). Some considerations of the import of the 2008 EPAS for curriculum design. Retrieved October 29, 2009 from http://www.cswe.org/NR/rdonlyres/42372F53-28A5-4939-A673-A0C9902A402C/0/2008EPASCurriculumDe sign.pdf

Howard, M., \& Jensen, J. (1999). Clinical practice guidelines: Should social work develop them? Research on Social Work Practice, 9(3), 283-301.

In re Adoption/Guardianship No. CCJ147146, 360 Md. 634, 759 A.2d 755 (September 13, 2000).

Jaffee v. Redmond 116 S. Ct. 1923 (June 13, 1966).

Jordan, C., \& Franklin, C. (2003). Clinical assessment for social workers ( $2^{\text {nd }}$ ed). Chicago: Lyceum.

Jordan, G., \& Stein, D. (2000). Mental disorders due to a general medical condition. Psychosomatics, 41(4), 370.

Keeton, W.P., Dobbs, D., Keeton, R., \& Owen, D. (1984). Prosser and Keeton on Torts (5 ${ }^{\text {th }}$ ed.). St. Paul, MN.: West Publishing.

Kirk, S., \& Hsieh, D. (2009). Do perceptions of dysfunction and normality mediate clinician's judgments of adolescent antisocial behavior? Social Service Review, 83(2), 245-266.

Kirk, S., \& Kutchins, H. (1988). Deliberate misdiagnosis in mental health practice. Social Service Review, 62(2), 225-237.

Kirk, S., Wakefield, J., Hsieh, D., \& Pottick, K. (1999). Social context and social workers’ judgment of mental disorder. Social Service Review, 73(1), 82-104.

Kutchins, H. (1991). The fiduciary relationship: The legal basis for social workers= responsibilities to clients. Social Work, 36(2), 106-113.

Kutchins, H., \& Kirk, S. (1986). The reliability of DSM-III: A critical review. Journal of Social Work Education, 22, 3-12. 
Kutchins, H., \& Kirk, S. (1987). DSM-III and Social Work Malpractice. Social Work, 32(3 ), 205-211.

Kutchins, H., \& Kirk, S. (1988). The business of diagnosis: DSM-III and clinical social work. Social Work, 33(3 ), 215-220.

Lillard, M. (May, 2008). The standard of care for medical malpractice claims in Idaho: Time for reassessment. The Advocate, 51(5), 19-20.

McQuaide, S. (1999). A social worker=s use of the Diagnostic and Statistical Manual. Families in Society, 80(4), 410-416.

Meyer, D., \& Simon, R. (2004). Psychiatric malpractice and the standard of care. In R. Simon (Ed.), The APA textbook of forensic psychiatry (185-203). Washington, DC: American Psychiatric Publishing.

Morrison, J. (1997). When psychological problems mask medical disorders: A guide for psychotherapists. New York: Guilford.

Morrison, J. (2007). Diagnosis made easier. New York: Guilford.

Muniz, A. (1999). Factors associated with misdiagnosis among social workers in mental health. Doctoral dissertation, Barry University.

Munson, C. (1997). The future of clinical social work and managed cost organizations. (1997). Psychiatric Services, 48(4), 479-82.

Munson, C. (2004). The evolution of protocol-based supervisory practice. In M. Austin \& K. Hopkins (Eds.), Supervision as collaboration in the human services (pp. 85-96). Thousand Oaks, CA.: Sage.

National Association of Social Workers (2005a). NASW standards for clinical social work in social work practice. Retrieved May 20, 2008 from http://www.socialworkers.org/practice/standards/NASWClinicalSWStandards.pdf

National Association of Social Workers (2005b). NASW standards for social work practice in health care settings. Retrieved May 20, 2008 from http://www.socialworkers.org/practice/standards/NASWHealthCareStandards.pdf.

National Practitioner Data Bank Public Use Data File. (June 30, 2009). Retrieved September 27, 2009 from http://www.npdb-hipdb.hrsa.gov/

Newman, B., Clemmons, V., \& Dannenfeiser, P. (2007). The Diagnostic and Statistical Manual of Mental Disorders in graduate social work education: Then and now. Journal of Social Work Education, 43(2), 297-307.

Olfson, M., Marcus, S., \& Pincus, H. (1999). Trends in office-based psychiatric practice. American Journal of Psychiatry, 156(3), 451-457.

Othmer, E., \& Othmer, S. (2002). The clinical interview using DSM-IV-TR. Washington, DC: American Psychiatric Association.

Parloff, M. (1982). Psychotherapy research evidence and reimbursement decisions: Bambi meets Godzilla. Am J Psychiatry, 139(6), 718-27.

People v. R.R., and People v. G.A., 12 Misc.3d 161, 807 N.Y.S.2d 516 (N.Y. Sup. Dec. 22, 2005) (combined cases). 
Peters, P. (2000). The quiet demise of deference to custom: Malpractice law at the millennium. Washington and Lee Law Review, 57(1), 163-205.

Priest, R. (1997). A patient who changed my practice. International Journal of Psychiatry in Clinical Practice, 1(3), 221-222.

Ramin, M., \& Olfson, M. (2008). National trends in psychotherapy by office-based psychiatrists. Archives of General Psychiatry, 65(8), 962-970.

Reamer, F. (1995). Malpractice claims against social workers: First facts. Social Work, 40(5), 595-601.

Reamer, F. (1998). Clients' right to competent and ethical treatment. Research on Social Work Practice, 8(5), 597-603.

Reamer, F. (2003). Social work malpractice and liability. New York: Columbia University Press.

Rosen, A., \& Proctor, E. (2003). Developing practice guidelines for social work intervention: Issues, methods, and research agenda. New York: Columbia University Press.

Rosenbaum, S., Kamoie, B., Mauery, D.R., \& Walitt, B. (2003). Medical necessity in private health plans: Implications for behavioral health care. DHHS Pub No. (SMA) 03-3790. Rockville, MD: Center for Mental Health Services, Substance abuse and Mental Health Services Association.

Rubin, A. \& Parrish, D. (2007). Views of evidence-based practice among faculty in master of social work programs: A national survey. Research on Social Work Practice, 17(1), 110-122.

Rubinson, E. (1999). DSM-IV: A comparison of social workers and psychiatrists on knowledge, attitudes, and behaviors. Doctoral dissertation, New York University.

Saltzman, A., \& Proch, K. (1990). Law in social work practice. Chicago: Nelson-Hall.

Shimabukuro, J. (2008). Role of thyroid in diagnostic assessment practices of Hawaii mental health providers. Doctoral dissertation, Argosy University/Hawai’i.

Siegel, D. (2008). The growing admissibility of expert testimony by clinical social workers on competence to stand trial. Social Work, 53(2), 153-163.

Tarasoff v. Regents of the University of California (17 Cal.3d 425 [1976]).

Taylor, M., \& Vaidya, N. (2005). Psychopathology in neuropsychiatry: DSM and beyond. Journal of Neuropsychiatry and Clinical Neuorsciences, 17(2), 246-249.

Turner, F. (2002). Diagnosis in social work: New imperatives. New York: Haworth.

U.S. Department of Health and Human Services. (1999). Mental Health: A Report of the Surgeon General. Rockville, MD: U.S. Department of Health and Human Services, Substance Abuse and Mental Health Services Administration, Center for Mental Health Services, National Institutes of Health, National Institute of Mental Health.

U.S. Department of Health and Human Services. (2006). National Practitioner Data Bank 2006 Annual Report. Retrieved September 27, 2009, from http://www.npdh-hipdb.hrsa.gov/annualrpt.html 
Wallen, M., \& Lorman, W. J. (2008). Special issues in patients with comorbid psychiatric and chemical dependency disorders. In J. Brick (Ed.), Handbook of the medical consequences of alcohol and drug abuse (2nd ed.) (579-621). NY.: Haworth Press.

Wilk, J., West, J., Narrow, W., Rae, D., \& Regier, D. (2005). Economic grand rounds: Access to psychiatrists in the public sector and in managed health plans. Psychiatric Services, 56(4), 408-10

Williams, C. (Winter, 2004). Evidence-based medicine in the law beyond clinical practice guidelines: What effect will E.M. have on the standard of care? Washington and Lee Law Review, 61(1), 479-534.

World Health Organization. (2007). International Statistical Classification of Diseases and Related Health Problems (10 ${ }^{\text {th }}$ Revision).Retrieved June 3, 2008 from http://www.who.int/classifications/apps/icd/icd10online/

Zimmerman, M. (2003). What should the standard of care for psychiatric evaluations be? The Journal of Nervous and Mental Disease, 191(5), 281-286. 